\title{
\begin{tabular}{l|l} 
Mibraries & DSpace@MIT
\end{tabular}
}

\author{
MIT Open Access Articles
}

\section{Treating Irrigation Water Using High-Performance Membranes for Monovalent Selective Electrodialysis}

The MIT Faculty has made this article openly available. Please share how this access benefits you. Your story matters.

Citation: Ahdab, Yvana D. et al. "Treating Irrigation Water Using High-Performance Membranes for Monovalent Selective Electrodialysis." ACS ES\&T Water (September 2020): doi.org/10.1021/ acsestwater.0c00012 (C) 2020 American Chemical Society

As Published: https://doi.org/10.1021/acsestwater.0c00012

Publisher: American Chemical Society (ACS)

Persistent URL: https://hdl.handle.net/1721.1/128539

Version: Author's final manuscript: final author's manuscript post peer review, without publisher's formatting or copy editing

Terms of use: Creative Commons Attribution-Noncommercial-Share Alike 


\title{
Treating irrigation water using
}

\section{high-performance membranes for monovalent selective electrodialysis}

Yvana D. Ahdab, Danyal Rehman, Georg Schücking, Maria Barbosa, and John H.

\author{
Lienhard $\mathrm{V}^{*}$ \\ Rohsenow Kendall Heat Transfer Laboratory, Massachusetts Institute of Technology, \\ 77 Massachusetts Avenue, Cambridge, MA 02139, United States \\ E-mail: lienhard@mit.edu
}

\begin{abstract}
The most common desalination technology for treating brackish irrigation water is reverse osmosis (RO). RO yields product waters low in monovalent ions harmful to crops $\left(\mathrm{Na}^{+}, \mathrm{Cl}^{-}\right)$ and in divalent ions that encourage crop growth $\left(\mathrm{Ca}^{2+}, \mathrm{Mg}^{2+}, \mathrm{SO}_{4}^{2-}\right)$. Fertilizer or divalentrich brackish water must be mixed with the desalinated water to reintroduce these nutrients. Monovalent selective electrodialysis (MSED) provides an alternative to RO that selectively extracts monovalent ions while retaining divalent ions. This paper investigates the monovalent selectivity and potential of the new cost-effective Fujifilm MSED membranes to treat brackish source water in greenhouses, with a comparison to the widely-used Neosepta MSED membranes. Thirteen groundwater compositions serve as feedwater to an MSED experimental set up to characterize membrane selectivity, ion transport, limiting current and membrane resistance. The Fujifilm membranes demonstrate notable selectivity for all compositions. On average, they remove six sodium ions, compared to Neosepta's four, for every calcium ion
\end{abstract}


and thirteen sodium ions, compared to Neosepta's seven, for every magnesium ion, while their bench-scale cost is $68 \%$ lower than that of the Neosepta membranes. The Fujifilm selectivity values are used to calculate annual fertilizer savings of MSED relative to RO, which average $\$ 4995 /$ ha for 6,000 brackish groundwaters across the U.S.

Keywords: desalination; groundwater; electrodialysis; agriculture; membrane selectivity 


\section{Introduction}

Agriculture is the dominant user of water supplies globally (69\% of freshwater withdrawals ${ }^{1}$ ). Given current trends in population growth and resource-intensive consumption, ${ }^{2,3}$ the agriculture sector must continue to develop and adopt more efficient farming practices to meet future water and food demand. Greenhouses represent such a solution: they yield more crops using fewer land and water resources than conventional open-air farming. A key component in optimizing greenhouse operations is irrigation water quality.

Greenhouses primarily depend on groundwater for irrigation. Because most groundwater is brackish $(0.5 \mathrm{mg} / \mathrm{L} \leq \mathrm{TDS} \leq 5 \mathrm{mg} / \mathrm{L})$, desalination is required to reduce the concentration of salts and toxic solutes, which would otherwise threaten crop productivity. In the U.S., for example, annual fresh groundwater usage is less than one-thirtieth the available volume of brackish groundwater (BGW) $(1,000 \mathrm{mg} / \mathrm{L} \leq \mathrm{TDS} \leq 10,000 \mathrm{mg} / \mathrm{L}) .{ }^{4}$ As a result, greenhouses increasingly rely on reverse osmosis (RO) to improve their source water quality. Although RO is the most widely used and cost-effective desalination technology, its posesses two disadvantages in agricultural applications. First, $\mathrm{RO}$ removes all ions from solution, including monovalent ions $\left(\mathrm{Na}^{+}, \mathrm{Cl}^{-}\right)$damaging to crops and divalent ions $\left(\mathrm{Ca}^{2+}, \mathrm{Mg}^{2+}, \mathrm{SO}_{4}^{2-}\right)$ favorable for crop growth. ${ }^{5}$ These nutrients must then be re-added to the desalinated water typically in the form of fertilizer. Second, RO's water recovery of approximately $80 \%$ is lower than that of other brackish water technologies, resulting in lesser water savings. ${ }^{6}$

Monovalent selective electrodialysis (MSED), a variant of electrodialysis (ED), provides an alternative to RO for greenhouses. Most notably, the technology selectively extracts harmful monovalent ions, while retaining divalent ions beneficial for crop growth in the desalinated water. This selective separation decreases fertilizer requirements and related costs. Moreover, MSED can operate at a water recovery greater than $90 \%,{ }^{7}$ saving more water and reducing the amount of brine for disposal and/or reuse. Other advantages of MSED include its 2-3 year increase in membrane lifetime relative to $\mathrm{RO}^{7}$ and its process reversal that makes its membranes less susceptible to foul- 
ing.

Despite the development of MSED in the 1960s, the technology has not been implemented to desalinate brackish water at the commercial scale. Instead, MSED membranes have historically been manufactured to concentrate seawater for salt production, i.e., for much higher salinities than those of brackish water. ${ }^{8}$ Only recently were MSED membranes developed specifically for brackish water applications by Fujifilm. Consequently, the literature has focused on MSED membrane selectivity in seawater and concentrated seawater, ${ }^{9-11}$ while only three studies,,${ }^{5,12,13}$ to our knowledge, examine MSED membrane selectivity in brackish waters.

Jiang et al. ${ }^{12}$ showed that the addition of a polyethyleneimine coating layer greatly enhances the monovalent selectivity of the CR67 membrane (Suez Water Technologies \& Solutions), although the membrane still proved to be divalent selective. Cohen et al. ${ }^{5}$ tested two MSED membranes on one BGW composition from Mashabei Sadeh, Israel: the CSO/ASV membranes (Asahi Glass) demonstrated selectivity towards monovalent ions, and the Neosepta CMS/ACS membranes (Astom Corporation) showed selectivity towards divalent ions. In contrast, Ahdab et al. ${ }^{13}$ concluded that, for 16 diverse BGW compositions, the Neosepta CMS/ACS membranes are monovalent selective.

This study performs the first analysis on the monovalent selectivity of the new Fujifilm Type 16 MSED membranes. Because BGW varies significantly with location, we conduct experiments on 13 diverse BGW compositions to evaluate membrane selectivity, membrane resistance, and limiting current density and to develop an MSED model for multi-ion transport. The relationship between membrane selectivity and BGW composition is then investigated. These results are compared to those of the well-established Neosepta CMS/ACS for the same feedwaters, ${ }^{13}$ in order to provide a benchmark for Fujifilm membrane performance. Finally, based on the experimentallydetermined membrane selectivities, we calculate fertilizer cost savings offered by MSED relative to $\mathrm{RO}$ for 6,000 divalent-rich BGWs across the U.S. and highlight areas that show promise for MSED adoption. 


\section{${ }_{71}$ Methods}

In an MSED system, two types of monovalent selective ion-exchange membranes, arranged in alternating order between two electrodes, separate a feed stream into a product (or diluate) stream and a concentrate stream. Anion exchange membranes (AEMs) and cation exchange membranes (CEMs) contain positively charged and negatively charged groups, respectively, fixed to their polymer matrix. ${ }^{7}$ The membranes employ Donnan exclusion to enable the selective charge-based migration of ionic species: ${ }^{14}$ AEMs allow the transport of monovalent anions, while rejecting divalent anions and all cations. Similarly, CEMs enable the transport of monovalent cations while rejecting divalent cations and all anions. The effectiveness of ion-exchange membranes depends on various parameters, such as the type and concentration of the fixed charges in the polymer, the hydrophobic or hydrophobic nature of the matrix polymer, the membrane morphology and the polymer network density. ${ }^{7}$

Spacers are placed between the membranes and electrodes, as well as the membranes themselves, in order to configure the flow. An applied potential difference across the electrodes induces ion transport across the membranes. Anions migrate towards the anode, while cations migrate towards the cathode.

Figure 1 demonstrates this process for an MSED system with two membranes treating brackish groundwater, typically source water for irrigation. The primary groundwater constituents are calcium, magnesium, sulfate, sodium and chloride. ${ }^{15}$ Sodium and chloride, which are monovalent ions, are damaging to crops. Calcium, magnesium, and sulfate, which are divalent ions, act as nutrients to crops. The MSED desalination process generates a diluate stream, containing low salinity and high nutrient concentrations, for irrigation and a concentrate stream, containing high salinity and high sodium chloride concentration, for disposal or reuse after treatment. Details of the experimental set-up and membrane specifications can be found in Section S1. 


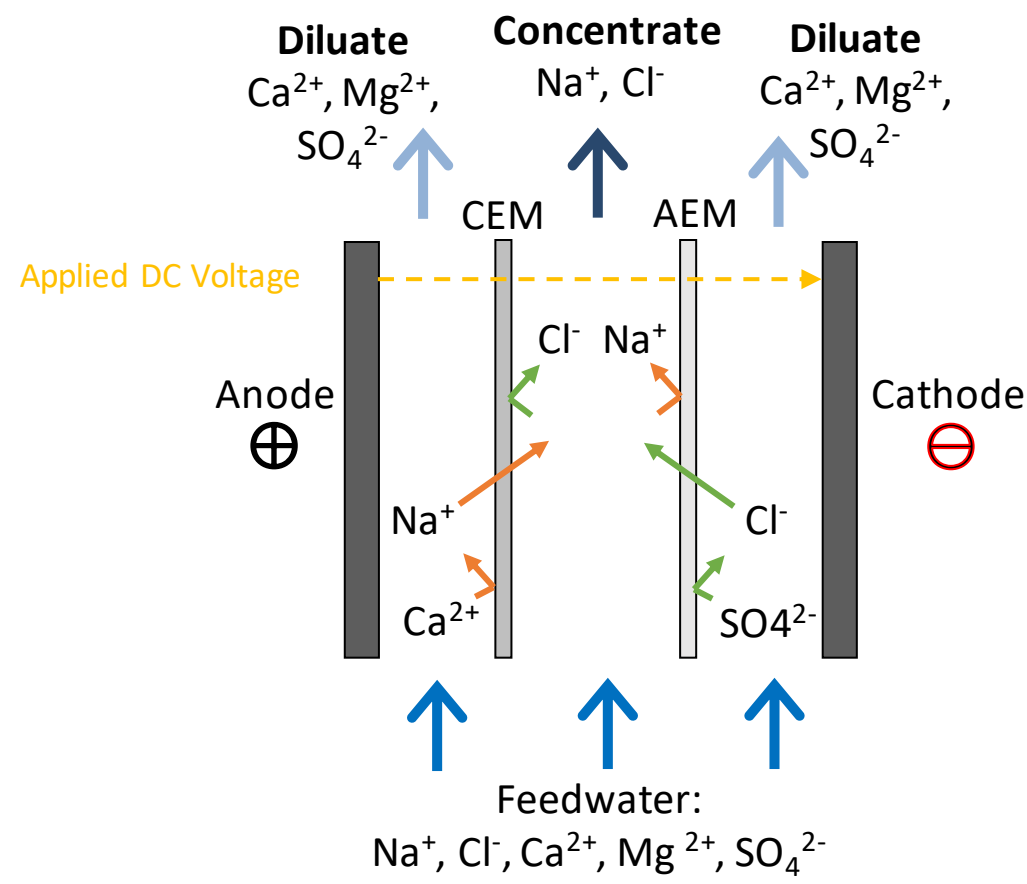

Figure 1: A simplified MSED stack consisting of two electrodes, a CEM, and a AEM (modified from Rehman et al. ${ }^{16}$ ). In reality, the number of membrane cell pairs is much greater. Groundwater serves as the feedwater. An applied voltage across the electrodes yields a diluate stream, high in nutrients and low in $\mathrm{NaCl}$, for irrigation and a concentrate stream for disposal. Magnesium, not shown here, will show similar behavior as calcium.

We may express the net salt and water transport across the membrane in each compartment of the MSED stack as

$$
\begin{gathered}
J_{s, j}=\frac{T_{s, j}^{c p} i}{z F}-L_{j}\left(C_{j, c, m}-C_{j, d, m}\right) \\
J_{w}=\frac{T_{w}^{c p} i}{F}+L_{w}\left(\pi_{j, c, m}-\pi_{j, d, m}\right)
\end{gathered}
$$

where $J$ is flux in $\mathrm{mol} \cdot \mathrm{m}^{-2} \cdot \mathrm{s}^{-1}, s$ denotes salt, $w$ denotes water, $T$ is a transport number, $F$ is Faraday's constant, $L$ is the membrane permeability in $\mathrm{m} \cdot \mathrm{s}^{-1}$ for the salts and in $\mathrm{s} \cdot \mathrm{m}^{-1}$ for the water, $z$ is the ion valence, $c$ denotes concentrate, $d$ denotes diluate, $m$ is membrane, $C$ is a concentration in $\mathrm{mol} \cdot \mathrm{m}^{-3}$, and $A_{m}$ is the membrane area in $\mathrm{m}^{2}$. The subscript $j$ represents an ion species in the groundwater that travels across the series of ion-exchange membranes. The applied current density 
$i$ is a function of Donnan potentials and ohmic resistances for the membranes, diluate, concentrate and rinse. The salt flux in eq 1 depends on ion migration (first term) and ion diffusion (second term), while the water flux in eq 2 depends on electro-osmosis (first term) and water diffusion (second term). In order to characterize the MSED Fujifilm membranes, we experimentally evaluate the following membrane parameters from these equations: ion transport numbers, membrane selectivity, membrane resistance (Section S4.2.2), and limiting current density (Section S4.2.1). These membrane parameters serve as inputs to an MSED model that we develop (Section S5.1.1).

\section{Brackish groundwaters analyzed}

In this study, BGW is defined as containing $500-10,000 \mathrm{mg} / \mathrm{L}$ of TDS. Because large variations in BGW occur with location, MSED experiments are conducted on 13 BGWs across the entire salinity range with different cation and solute ratios which can be written as:

$$
\begin{gathered}
r_{\text {cation }}=\frac{C_{\mathrm{Ca}^{2+}}+C_{\mathrm{Mg}^{2+}}}{C_{\mathrm{Na}^{+}}+C_{\mathrm{Ca}^{2+}}+C_{\mathrm{Mg}^{2+}}} \\
r_{\text {anion }}=\frac{C_{\mathrm{SO}_{4}{ }^{2-}}}{C_{\mathrm{Cl}^{-}}+C_{\mathrm{SO}_{4}{ }^{2-}}}
\end{gathered}
$$

These compositions are derived from the BGW samples in the U.S. Geological Survey (USGS) major-ions dataset ${ }^{17}$ (Section S3) and the Cohen et al. study, which investigates MSED treatment for irrigation water: ${ }^{5}$ four dilutions $(1500-10000 \mathrm{mg} / \mathrm{L})$ of Comp. $1\left(r_{\text {cation }}=0.40, r_{\text {anion }}=0.40\right)$, Comp. $2\left(r_{\text {cation }}=0.60, r_{\text {anion }}=0.14\right)$, and Comp. $3\left(r_{\text {cation }}=0.21, r_{\text {anion }}=0.64\right)$ and one dilution $(3000 \mathrm{mg} / \mathrm{L})$ of Cohen $\left(r_{\text {cation }}=0.24, r_{\text {anion }}=0.30\right)$ are tested. More detail on feedwater composition data can be found in Section S2. 
The sodium adsorption ratio (SAR) of the product waters is defined as:

$$
S A R=\frac{W_{\mathrm{Na}^{+}}}{\sqrt{0.5\left(W_{\mathrm{Ca}^{+}}+W_{\mathrm{Mg}^{+}}\right)}}
$$

where $W$ is ion concentration in milliequivalents per liter. As a general rule, waters with low SAR $(\mathrm{SAR} \leq 3)$ have no limitations on irrigation use; waters with a higher SAR $(3 \leq \mathrm{SAR} \leq 9)$ have slight to moderate limitations on irrigation use. ${ }^{18}$

\section{Transport number}

To evaluate ion transport numbers, we conduct experiments at constant current and measure the change in ion concentrations in the diluate over time. A minimum of three trials was run at each set of conditions for $13 \mathrm{BGW}$ solutions to establish repeatability. In each trial, simulated groundwater was added to the concentrate and diluate streams as feedwater. The pumps and power supply were then switched on to circulate the three streams and apply a constant current across the stack, respectively. We ensure that $i / i_{\text {lim }}$ does not surpass 0.7 , a standard operating condition in commercial ED systems treating brackish water. ${ }^{19}$ The ion transport number may be formulated from eq 1 as:

$$
T_{s, j}^{c p}=\frac{\Delta w_{j} F}{i \Delta t A_{m} N_{c p}}
$$

where $\Delta w_{j}$ is the change in ion concentration in milliequivalents relative to the initial ion concentration at $t=0, N_{c p}$ is the number of cell pairs, and $A_{m}$ is the membrane area in $\mathrm{m}^{2}$. Applying the Hittorf method, we neglect the the ion diffusion term in eq 1, which is approximately three orders of magnitude less than the ion migration term. McGovern et al. ${ }^{20}$ have verified this trend even for high salinity applications. 


\section{Membrane permselectivity}

Based on ion transport numbers, membrane permselectivity $P$ is defined such that it captures the membranes' selective removal of monovalent relative to divalent ions. This parameter is equivalent to the ratio of the divalent to monovalent transport numbers, normalized by their initial ion concentrations at $t=0$ :

$$
P_{m o n}^{d i v} \equiv \frac{T_{d i v} / w_{d i v, o}}{T_{m o n} / w_{m o n, o}}
$$

Permselectivity values between zero and unity indicate correspond to membrane monovalent selectivity. Permselectivities closer to unity denote worse rejection of monovalent ions and suggest a less efficient MSED system, while permselectivities closer to zero correlate to greater monovalent selectivity.

\section{Results}

This section presents experimental results of membrane monovalent selectivity for a bench-scale MSED system containing Fujifilm membranes. Results for membrane resistance, limiting current density and our transport model can be found in Sections S4 and S5. Because BGW composition varies significantly with location, we analyze 13 diverse BGWs to characterize Fujifilm membrane selectivity. Trends in selectivity and BGW composition, both TDS and solute ratio, are explored. Our results suggest that membrane selectivity may be sensitive to solute ratio and is independent of BGW salinity. In order to benchmark Fujifilm membrane behavior, we compare these outcomes to those of the widely used Neosepta membranes.

All results represent a bench-scale setup. System parameters may vary with scale for a variety of reasons, including differences in transport characteristics, operating conditions and system configurations. Consequently, pilot studies in greenhouses are required to fully characterize MSED systems for real-world applications. 


\section{Permselectivity for 13 BGW compositions}

The Fujifilm CEMs and AEMs show notable selectivity towards monovalent ions across the 13 BGW compositions. The average magnesium selectivity is $0.08 \pm 0.04$, representing a factor of 8.3-26 removal of sodium relative to magnesium. The average calcium permselectivity is $0.18 \pm 0.08$, corresponding to a factor of $3.7-10$ reduction of sodium relative to calcium. The lower hydration energy of calcium (1592 kJ/mol) compared to magnesium (1904 kJ/mol) accounts for calcium's higher permselectivity (i.e., lower removal rate), because ions must partly or entirely shed their hydration shell to traverse the membranes. ${ }^{21}$ Average sulfate permselectivity across all compositions is $0.18 \pm 0.12$, corresponding to a factor of 3.3-20 removal of chloride relative to sulfate. The maximum standard deviation $\sigma$ from the average values is $25 \%$ for cations and $33 \%$ for anions. The permselectivities for each BGW solution are shown in Table 1. The SARs of Comp. 1, Comp. 2, Comp. 3 and Cohen product waters are $1.8 \pm 0.7,1.6 \pm 0.4,3.6 \pm 0.3$, and $2.2 \pm 0.4$, respectively.

Table 1: Calcium, magensium and sulfate permselectivity for 13 BGW compositions. The first two columns correspond to BGW composition.

\begin{tabular}{ccccc}
\hline Solute ratio & $\mathrm{TDS}(\mathrm{mg} / \mathrm{L})$ & $P_{\mathrm{Na}}^{\mathrm{Ca}}$ & $P_{\mathrm{Na}}^{\mathrm{Mg}}$ & $P_{\mathrm{Cl}}^{\mathrm{SO}_{4}}$ \\
\hline & 1295 & $0.21 \pm 0.03$ & $0.09 \pm 0.02$ & $0.21 \pm 0.02$ \\
Comp. 1 & 2858 & $0.14 \pm 0.03$ & $0.06 \pm 0.02$ & $0.18 \pm 0.10$ \\
& 4408 & $0.19 \pm 0.03$ & $0.09 \pm 0.02$ & $0.16 \pm 0.02$ \\
& 10396 & $0.16 \pm 0.04$ & $0.09 \pm 0.03$ & $0.27 \pm 0.02$ \\
\hline \multirow{3}{*}{ Comp. 2 } & 1483 & $0.18 \pm 0.02$ & $0.05 \pm 0.002$ & $0.10 \pm 0.01$ \\
& 2895 & $0.10 \pm 0.05$ & $0.06 \pm 0.004$ & $0.12 \pm 0.01$ \\
& 4756 & $0.19 \pm 0.02$ & $0.10 \pm 0.002$ & $0.15 \pm 0.008$ \\
& 7814 & $0.22 \pm 0.02$ & $0.09 \pm 0.003$ & $0.10 \pm 0.01$ \\
\hline \multirow{3}{*}{ Comp. 3 } & 1450 & $0.13 \pm 0.03$ & $0.07 \pm 0.02$ & $0.22 \pm 0.04$ \\
& 2683 & $0.22 \pm 0.03$ & $0.10 \pm 0.01$ & $0.28 \pm 0.01$ \\
Cohen & 4276 & $0.22 \pm 0.02$ & $0.05 \pm 0.007$ & $0.23 \pm 0.01$ \\
& 8491 & $0.21 \pm 0.01$ & $0.09 \pm 0.002$ & $0.18 \pm 0.02$ \\
\hline
\end{tabular}




\section{Observed trends in solute ratio at fixed TDS}

We explore trends in solute ratio with transport number and monovalent selectivity for Comp. 1, Comp. 2, Comp. 3 and Cohen solutions at a fixed TDS of $2750 \pm 154 \mathrm{mg} / \mathrm{L}$. Transport number linearly depends on solute ratio (Section S5.3), with monovalent transport numbers decreasing and divalent transport numbers increasing with cation and anion solute ratio. At lower solute ratios, fewer divalent ions will compete with monovalent ions to cross the membranes, resulting in increased monovalent transport and decreased divalent transport. Conversely, at higher solute ratios, monovalent ions will compete with more divalent ions to cross the membranes, leading to reduced monovalent transport and greater divalent transport.

Figure 2 illustrates the linear relationship between permselectivity and solute ratio. Anion permselectivity increases with anion solute ratio, while cation permselectivity decreases with cation solute ratio. Differences in the rate of change in transport number ratio with solute ratio for anions and cations seem to account for the discrepancy in the permselectivity trends. Trends in permselectivity mirror those in transport number ratio, because solute ratio is proportional to the initial concentration ratio (i.e., $P_{m o n}^{d i v} \propto \frac{T_{d i v} / T_{m o n}}{r}$ ). If we divide the transport number ratio equations in Figure 2(c) by $r$, anion permselectivity varies with $A\left(r_{\text {anion }}\right)^{1.7}$ and cation permselectivity varies with $B+D / r_{\text {cation }}$, where $A, B$, and $D$ are constants greater than 0 . Consequently, anion permselectivity increases as $r_{\text {anion }}$ increases, while cation permselectivity decreases as $r_{\text {cation }}$ increases. The overlapping error bars in membrane selectivity suggest that the parameter may be sensitive to solute ratio. 


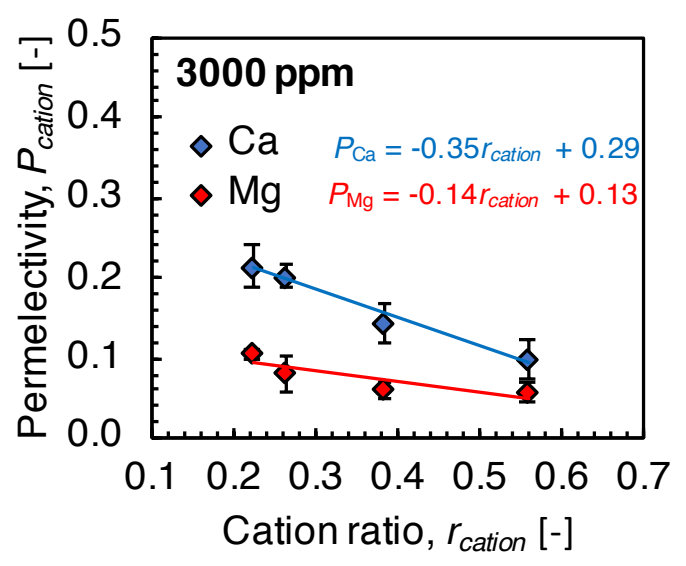

(a)

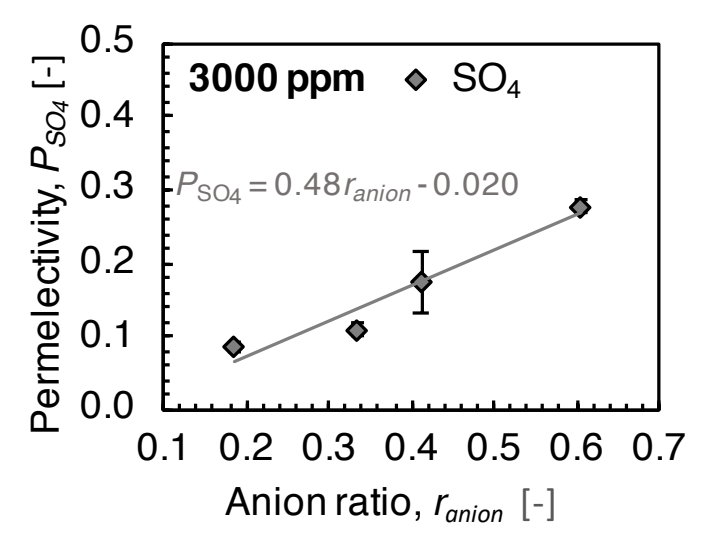

(b)

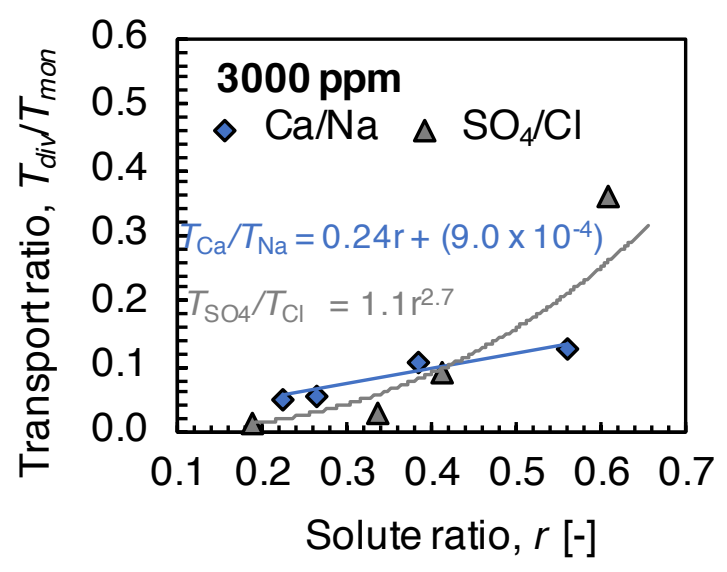

(c)

Figure 2: (a) CEM selectivity, (b) AEM selectivity, and (c) ratio of divalent to monovalent transport number for CEMs and AEMs, as a function of cation and anion solute ratio, respectively, for BGWs containing a TDS of $3000 \mathrm{mg} / \mathrm{L}$. 
Counter-ion (i.e., an ion with an electric charge opposite to the membrane) permselectivity may be influenced by co-ion (i.e., an ion with the same electric charge as the membrane) concentrations. For example, Comp. $3\left(r_{\text {anion }}=0.64\right)$ and Cohen $\left(r_{\text {anion }}=0.30\right)$ have substantially different anion solute ratios and relatively similar cation solute ratios (13\% difference). At a fixed TDS of $2624 \pm 83.6$, the average calcium permselectivity is $0.21 \pm 0.02(\sigma$ of $6 \%)$, suggesting little variation in calcium permselectivity despite differences in sulfate concentration. In comparison, the average magnesium permselectivity is $0.09 \pm 0.04$ ( $\sigma$ of $18 \%)$, reflecting a larger variation in permselectivity with differences in sulfate levels. More BGWs with similar counter-ion and different co-ion solute ratios would need to be analyzed to establish the effect of co-ions on counter-ion permselectivity.

\section{Observed trends in TDS at fixed solute ratio}

This section investigates trends in transport number and monovalent selectivity with initial diluate salinity, when the initial solute ratio is held constant. Although the TDS of most BGW samples in the USGS dataset range from $500 \mathrm{mg} / \mathrm{L}$ to $3,000 \mathrm{mg} / \mathrm{L},{ }^{15}$ we consider four salinities in the $1,000 \mathrm{mg} / \mathrm{L}$ to $10,000 \mathrm{mg} / \mathrm{L} \mathrm{BGW}$ range per ionic composition for completeness. We observe no trends in transport number as a function of initial diluate salinity for Comp. 1, Comp. 2, and Comp. 3 (Section S5.3). Moreover, the overlapping error bars illustrate the insignificant variation in a given ion transport number across the BGW salinity range. Because permselectivity is only a function of transport numbers at a constant solute ratio, there similarly appear to be no trends in permselectivity with initial salinity (Figure 3). The lack of observed trends may stem from the narrowness of the BGW salinity range compared to the broad salinity range typically considered in ED transport number fits in the literature (e.g, BGW salinities up to $200,000 \mathrm{mg} / \mathrm{L}$ ). ${ }^{20}$ 


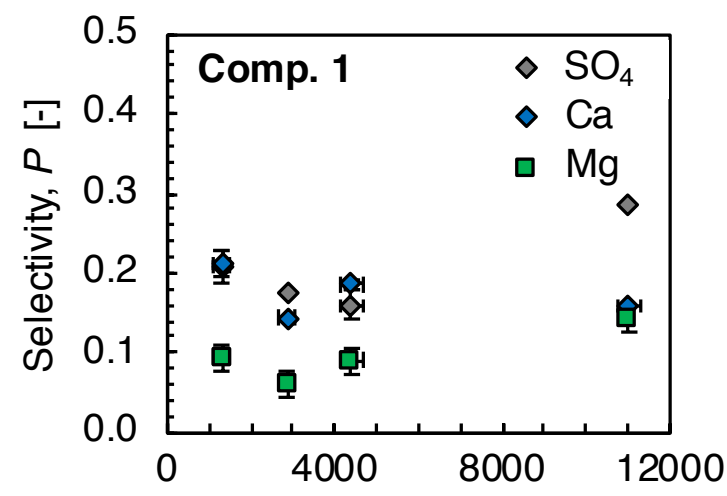

Total Dissolved Solids, TDS (mg/L)

(a)

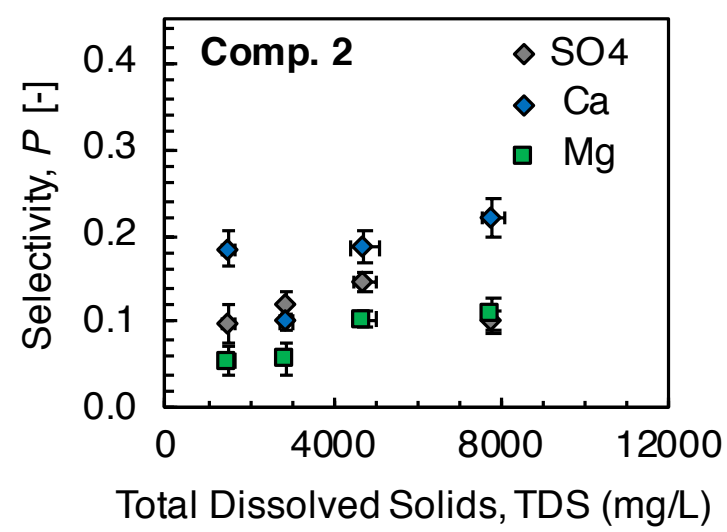

(b)

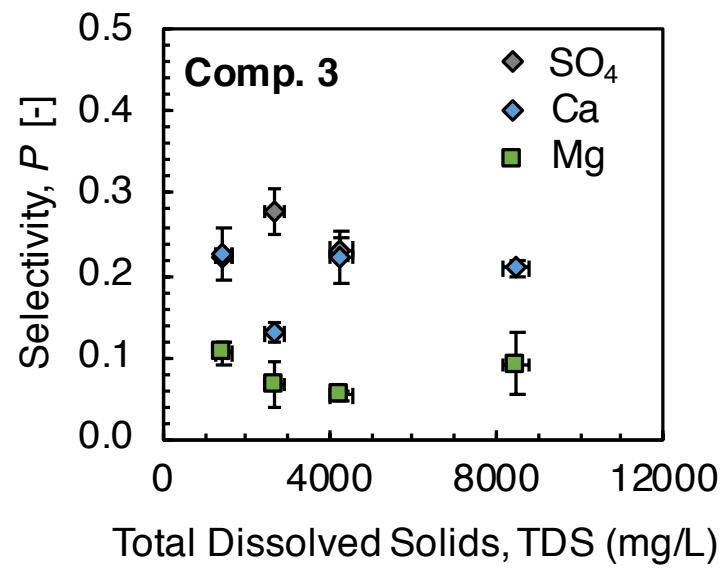

(c)

Figure 3: Membrane permselectivity as a function of TDS for (a) Comp. 1, (b) Comp. 2, and (c) Comp. 3. 


\section{Comparison to Neosepta MSED membranes}

This section compares the performance in the BGW salinity range of the recently developed Fujifilm membranes to the widely used Neosepta MSED membranes. The Neosepta membranes are characterized for the same 13 BGW compositions as the Fujifilm membranes. ${ }^{13}$ Across these compositions, Fujifilm CEMs show notably better monovalent selectivity, while the Fujifilm AEMs show moderately worse monovalent selectivity, than the Neosepta membranes (Table 2). The average Fujifilm calcium and magnesium permselectivities are $28 \%$ and $47 \%$, respectively, less than those of Neosepta. If we account for standard deviation $\left(P_{\mathrm{avg}} \pm 2 \sigma\right)$, the Neosepta CEMs remove a factor of 3.1-5.2 more sodium than calcium, in comparison to Fujifilm's 3.7-10, and a factor of 4.8-11 more sodium than magnesium, in comparison to Fujifilm's 8.3-26. The average Fujifilm sulfate permselectively is $4.1 \%$ less than that of Neosepta. If we account for standard deviation $\left(P_{\text {avg. }} \pm 2 \sigma\right)$, the Neosepta AEMs remove a factor of 4.3-9.4 more chloride than sulfate, in comparison to Fujifilm's 3.3-20. Considering CEM and AEM performance, Fujifilm membrane performance overall is superior to that of Neosepta for BGWs. In addition, the Fujifilm and Neosepta membranes show similar trends in permselectivity with BGW composition. There appears to be no relationship between permselectivity and TDS and a linear relationship between permselectivity and solute ratio. Cation and anion permselectivity increases with decreasing cation and increasing anion solute ratio, respectively, for both membranes (Section S5.4). However, the Fujifilm membranes have a larger selectivity-solute ratio slope for calcium and sulfate, suggesting that permselectivity of the Fujifilm membranes may be more sensitive to solute ratio than the Neosepta membranes. In addition, the Fujifilm membranes have a higher limiting current density than the Neosepta membranes, i.e., they can withstand a higher operating current without a decrease in performance. A detailed comparison of limiting current density and membrane resistance can be found in Section S4.3. 
Table 2: Calcium, magnesium and sulfate permselectivities of Neosepta and Fujifilm membranes for four solute ratios (Comp. 1, Comp. 2, Comp. 3, Cohen) and for all 13 analyzed BGWs. The Comp. 1, Comp. 2, and Comp. 3 values are averaged across their four tested salinities, because no trends in permselectivity with TDS are observed for either membrane.

\begin{tabular}{lcccccc}
\hline & \multicolumn{2}{c}{$P_{\mathrm{Na}}^{\mathrm{Ca}}$} & \multicolumn{2}{c}{$P_{\mathrm{Na}}^{\mathrm{Mg}}$} & \multicolumn{2}{c}{$P_{\mathrm{Cl}}^{\mathrm{SO}_{4}}$} \\
& Fujifilm & Neosepta & Fujifilm & Neosepta & Fujifilm & Neosepta \\
\cline { 2 - 7 } Comp. 1 & $0.17 \pm 0.03$ & $0.26 \pm 0.03$ & $0.08 \pm 0.02$ & $0.14 \pm 0.02$ & $0.20 \pm 0.06$ & $0.15 \pm 0.04$ \\
Comp. 2 & $0.17 \pm 0.05$ & $0.23 \pm 0.03$ & $0.08 \pm 0.02$ & $0.13 \pm 0.03$ & $0.12 \pm 0.06$ & $0.15 \pm 0.03$ \\
Comp. 3 & $0.20 \pm 0.04$ & $0.27 \pm 0.04$ & $0.08 \pm 0.02$ & $0.17 \pm 0.03$ & $0.23 \pm 0.08$ & $0.20 \pm 0.06$ \\
Cohen & $0.20 \pm 0.03$ & $0.27 \pm 0.04$ & $0.08 \pm 0.04$ & $0.16 \pm 0.04$ & $0.11 \pm 0.04$ & $0.16 \pm 0.04$ \\
\cline { 2 - 7 } All BGWs & $0.18 \pm 0.08$ & $0.26 \pm 0.06$ & $0.08 \pm 0.04$ & $0.15 \pm 0.06$ & $0.18 \pm 0.12$ & $0.17 \pm 0.06$ \\
\hline
\end{tabular}

\section{Implications for desalination in greenhouses}

Our experiments confirm the monovalent selectivity of Fujifilm and Neosepta membranes, with a better Fujifilm CEM performance, in the BGW salinity range. An MSED system using either set of membranes will be capable of retaining nutrients present in the source groundwater, which would otherwise be added as fertilizer after RO treatment. This section presents a first-order estimate of MSED fertilizer savings relative to RO for BGWs with sufficient nutrient concentrations from the 2017 USGS major-ions groundwater dataset. ${ }^{17}$ We then compare the Fujifilm and Neosepta results and conduct a case study on a 10 hectare greenhouse using MSED versus RO.

\section{Fertilizer cost savings}

MSED fertilizer cost savings are calculated for $6,000 \mathrm{BGWs}$ that contain nutrient concentrations in excess of general recommendations for irrigation water quality (Section S3): Ca $>150 \mathrm{mg} / \mathrm{L}, \mathrm{Mg}$ $>50 \mathrm{mg} / \mathrm{L}$, and/or $\mathrm{SO}_{4}>50 \mathrm{mg} / \mathrm{L} .{ }^{22,23}$ In reality, the desired irrigation water will depend on crop. However, we aim to provide a first-order approximation of MSED fertilizer savings independent of crop. We do not consider sulfate in our calculations of fertilizer savings, because multiple salts that compose fertilizer contain sulfate but not magnesium or calcium. Consequently, the determined 
fertilizer savings, based only on cations, serve as a lower bound on the nutrient savings potentially offered by MSED.

To characterize the membranes, we use the average cation permselectivities for the $13 \mathrm{BGW}$ compositions. The average cation selectivities have a maximum $\sigma$ of $25 \%$, which may result from differences in BGW solute ratio and appears to not result from differences in BGW salinity. Consequently, the Fujifilm selectivity values for 13 diverse BGW compositions can likely be applied to BGWs across the U.S. We set the final concentration of calcium, the key ion in determining fertilizer cost savings, to $150 \mathrm{mg} / \mathrm{L}$. Equation 7 is applied to evaluate the final magnesium concentrations and sodium concentrations, which do not exceed $100 \mathrm{mg} / \mathrm{L} .{ }^{24}$ We then compare the final nutrient concentrations of MSED and RO, based on typical RO ion percent reductions ranging from $90 \%$ to $99 \%$ (Section S7). The difference in these values is used to quantify the MSED Fujifilm savings in ion percent reductions $S_{\%, d i v}(\%)$, final ion concentrations $S_{p p m, d i v}(\mathrm{mg} / \mathrm{L})$, and fertilizer cost $S_{\$, d i v}\left(\$ \cdot \mathrm{ha}^{-1} \cdot \mathrm{yr}^{-1}\right)$ relative to $\mathrm{RO}$, assuming one growing season per year, in Table 3:

$$
\begin{gathered}
S_{\%, d i v}=100 \frac{\left(C_{d i v, i}-C_{d i v, f \mid R O}\right)-\left(C_{d i v, i}-C_{d i v, f \mid M S E D}\right)}{C_{d i v, i}} \\
S_{p p m, d i v}=\frac{S_{\%, d i v}}{100} C_{d i v, i} \\
S_{\$, d i v}=\left(S_{p p m, d i v}\right)\left(\mathrm{F}_{\text {cost }, \text { div }}\right)
\end{gathered}
$$

where $\mathrm{F}_{\text {cost } \text {,div }}$ is the fertilizer cost of adding gypsum ${ }^{25}$ or epsom ${ }^{26}$ to greenhouse soil (Section S6). 
Table 3: MSED Fujifilm savings in ion percent reductions, final ion concentrations and fertilizer cost relative to RO for $C_{\mathrm{Ca}, f}=150 \mathrm{mg} / \mathrm{L}$ and 9 different cases of $P_{N a}^{C a}$ and $P_{N a}^{M g}$ (avg., $+\sigma,-\sigma$ ). For example, the first row (average $P_{N a}^{C a}$ and $P_{N a}^{M g}$ ) uses the average permselectivity values. The last column includes the Neosepta fertilizer cost savings for comparison.

\begin{tabular}{|c|c|c|c|c|c|c|c|c|c|}
\hline \multirow[b]{2}{*}{$P_{\mathrm{Na}, \text { avg. }}^{\mathrm{Ca}}$} & \multirow[b]{2}{*}{$P_{\mathrm{Na}, \text { avg. }}^{\mathrm{Mg}}$} & \multicolumn{7}{|c|}{ Fujifilm } & \multirow{2}{*}{$\begin{array}{c}\text { Neosepta } \\
S_{\$, \mathrm{Ca}+\mathrm{Mg}}\end{array}$} \\
\hline & & $S_{\%, \mathrm{Ca}}$ & $S_{\%, \mathrm{Mg}}$ & $S_{p p m, \mathrm{Ca}}$ & $S_{p p m, \mathrm{Mg}}$ & $S_{\$, \mathrm{Ca}}$ & $S_{\$, \mathrm{Mg}}$ & $S_{\$, \mathrm{Ca}+\mathrm{Mg}}$ & \\
\hline avg. & avg. & 79 & 94 & 133 & 82 & $\$ 3587$ & $\$ 1408$ & $\$ 4995$ & $\$ 4942$ \\
\hline avg. & $+\sigma$ & 79 & 93 & 133 & 81 & $\$ 3587$ & $\$ 1389$ & $\$ 4977$ & $\$ 4915$ \\
\hline avg. & $-\sigma$ & 79 & 96 & 133 & 83 & $\$ 3587$ & $\$ 1426$ & $\$ 5013$ & $\$ 4969$ \\
\hline$+\sigma$ & avg. & 77 & 94 & 133 & 84 & $\$ 3575$ & $\$ 1435$ & $\$ 5010$ & $\$ 4944$ \\
\hline$+\sigma$ & $+\sigma$ & 77 & 93 & 133 & 83 & $\$ 3575$ & $\$ 1416$ & $\$ 4991$ & $\$ 4917$ \\
\hline$+\sigma$ & $-\sigma$ & 77 & 96 & 133 & 85 & $\$ 3575$ & $\$ 1453$ & $\$ 5028$ & $\$ 4970$ \\
\hline$-\sigma$ & avg. & 82 & 94 & 134 & 82 & $\$ 3600$ & $\$ 1398$ & $\$ 4998$ & $\$ 4948$ \\
\hline$-\sigma$ & $+\sigma$ & 82 & 93 & 134 & 81 & $\$ 3600$ & $\$ 1379$ & $\$ 4980$ & $\$ 4922$ \\
\hline$-\sigma$ & $-\sigma$ & 82 & 96 & 134 & 83 & $\$ 3600$ & $\$ 1415$ & $\$ 5016$ & $\$ 4975$ \\
\hline
\end{tabular}

Figure 4 maps the Fujifilm fertilizer cost savings $S_{\$, \mathrm{Ca}+\mathrm{Mg}}$ for the first row from Table $3\left(P_{\mathrm{Na}, \text { avg. }}^{\mathrm{Ca}}, P_{\mathrm{Na}, \text { avg. }}^{\mathrm{Mg}}\right)$. MSED can generate fertilizer savings for BGWs across the U.S., including agriculture centers in California's Central Valley, Iowa and the Dakotas. 


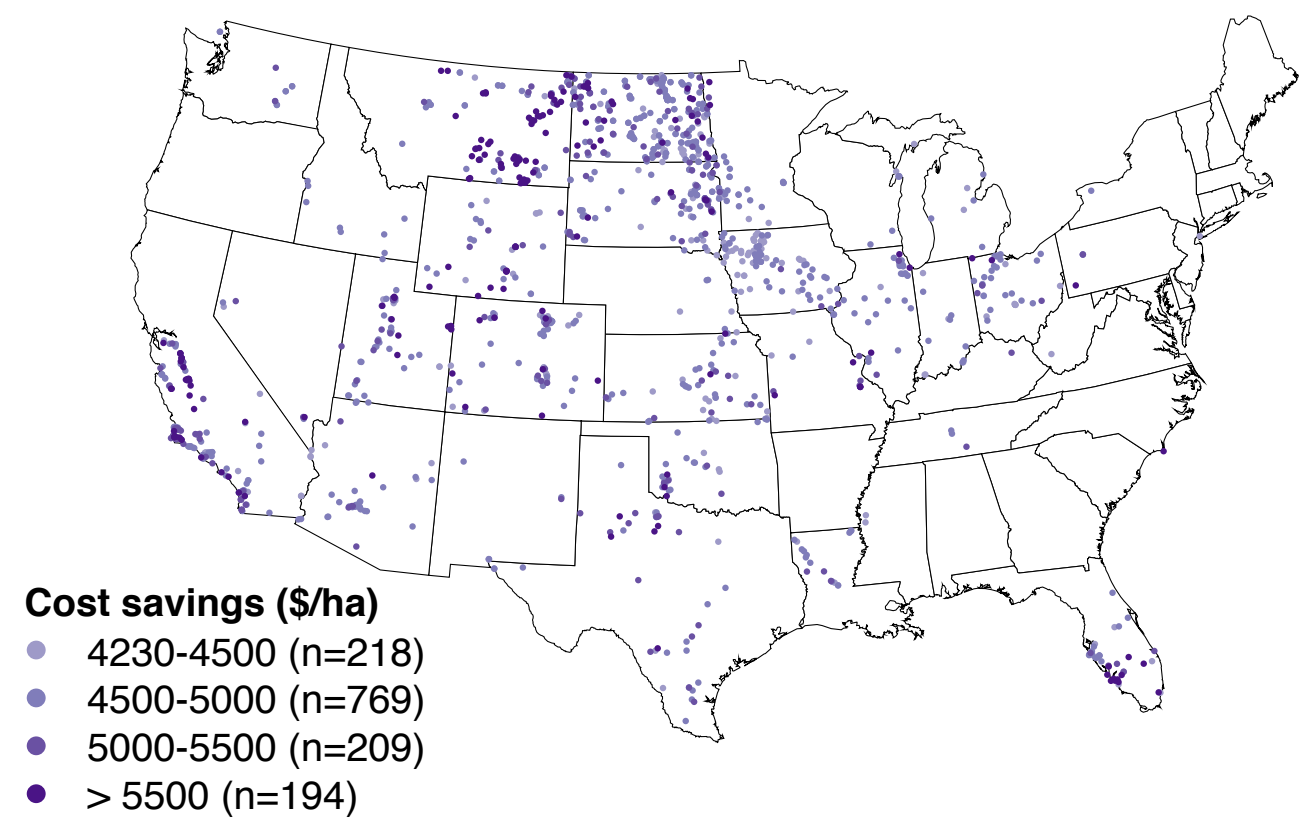

Figure 4: Map of Fujifilm fertilizer cost savings ( $\$ /$ ha.) for cations in BGW samples from the USGS dataset. Each dot corresponds to a BGW sample.

\section{Greenhouse case study: MSED versus RO}

RO is a commodity product with lower operating costs (OPEX) and capital costs (CAPEX) than MSED. Consequently, if MSED using Fujifilm or Neosepta membranes is to be implemented rather than RO in greenhouses, MSED savings must offset OPEX and CAPEX differences between the technologies within a two year payback period, according to greenhouse interviews we conducted. ${ }^{24}$ We anticipate larger farms being the early adopters of this promising technology. In addition to their greater resilience to innovation, the tradeoff between MSED savings and costs becomes more favorable, i.e., the payback period decreases, with an increase in farm size: CAPEX and OPEX grow at a decreasing rate with farm area, while MSED fertilizer savings linearly increase with farm area.

This case study compares the adoption of MSED and RO in a 10 hectare farm with a source water containing $850 \mathrm{mg} / \mathrm{L}$ in TDS. All cost data for RO and MSED is obtained from Nayar et al. ${ }^{24}$ The study assumes a desalination system capacity of $60 \mathrm{~m}^{3} /$ day-ha with a $90 \%$ capacity factor and 12 
hrs/day of operation. We define the annual fertilizer savings as $\$ 4,995 /$ ha, based on the average value for the Fujifilm membranes. Water savings are calculated using recovery values of $80 \%$ and 90\% for RO and MSED, respectively. The net cost of the technologies after one year of operation is then evaluated as:

$$
\text { Net cost }(\text { year one })=\operatorname{CapEx} \frac{\mathrm{r}(1+\mathrm{r})^{\mathrm{n}}}{(1+\mathrm{r})^{\mathrm{n}}-1}+\text { OpEx }- \text { savings }
$$

where $r$ corresponds to an annual interest rate of $8 \%^{27}$ and $n$ corresponds to a time period of 15 years, the life expectancy of RO and MSED systems. ${ }^{24}$ RO savings are equal to zero. For the 10 hectare farm, the net cost of MSED is less than that of RO after one year of operation, i.e., the payback period for greenhouses is less than one year (Table 4). MSED with Fuijfilm membranes annually saves greenhouses $\$ 39,719$ in fertilizer and $\$ 44,099$ in fertilizer and water relative to RO.

Table 4: MSED and RO net costs after one year of operation for a 10 hectare farm, based on annual capital and operating costs, as well as fertilizer and/or water savings. The MSED net costs are negative due to the fact that the annual savings exceed the total costs. MSED savings relative to RO are equivalent to the difference in their net costs. CapEx and OpEx data are obtained from Nayar et al. ${ }^{24}$

\begin{tabular}{ccc}
\hline & \multicolumn{1}{c}{ MSED } & \multicolumn{1}{c}{ RO } \\
\cline { 2 - 3 } Annual CapEx & $\$ 16,835$ & $\$ 13,540$ \\
\cline { 2 - 3 } OpEx & $\$ 17,799$ & $\$ 10,863$ \\
\cline { 2 - 3 } Fertilizer savings & $\$ 49,950$ & - \\
Net cost (year one) & $-\$ 15,316$ & $\$ 24,403$ \\
\cline { 2 - 3 } Water savings & $\$ 4,380$ & - \\
Net cost (year one) & $-\$ 19,696$ & $\$ 28,135$ \\
\hline
\end{tabular}

\section{Cost comparison to Neosepta MSED membranes}

MSED with Fujifilm or Neosepta ion exchange membranes demonstrates notable potential to further optimize greenhouse operations, as the resulting nutrient and water savings may offer a more sustainable, cost-effective option than RO. In comparison to the Neosepta membranes, the Fujifilm 
membranes yield a minimal increase $(<2 \%)$ in fertilizer cost savings per hectare (Table 3$)$ and in fertilizer and water savings for the 10 hectare case study: MSED with Neosepta membranes annually saves greenhouses $\$ 43,569,{ }^{13}$ in comparison to Fujifilm's $\$ 44,099$, in fertilizer and water relative to RO. Consequently, the key consideration in MSED membrane selection becomes cost per membrane area $\left(\$ / \mathrm{m}^{2}\right.$ of $\left.A_{m}\right)$. At the lab scale $\left(A_{m}<10 \mathrm{~m}^{2}\right)$, the Fujifilm membrane cost ${ }^{28}$ is approximately $\$ 162 / \mathrm{m}^{2}$ in comparison to the Neosepta membrane cost ${ }^{29}$ of $\$ 503 / \mathrm{m}^{2}$, reflecting the promise of the new Fujifilm MSED membranes. Nonetheless, the minimal difference in fertilizer cost savings, despite the notable difference in performance, between the Fujifilm and Neosepta membranes at the bench-scale suggests that entirely new membranes tailored towards brackish waters like Fujifilm may not need to be developed. Cost-effective manufacturing innovations (e.g., cheaper materials) for membranes already on the market that are tailored towards higher salinities, such as the Neosepta CMS/ACS membranes, may suffice for brackish water applications. However, pilot tests in greenhouses must be conducted to ensure that the membranes perform similarly at scale.

\section{Acknowledgments}

The authors would like to thank the National Science Foundation and the Bureau of Reclamation under Agreement Number R17AC00135 for funding the research reported in this paper. Additional support was provided by the Centers for Mechanical Engineering Research and Education at MIT and SUSTech (MechERE Centers at MIT and SUSTech).

\section{Supporting Information}

The supporting information includes the following sections:

S1 Experimental set-up

S2 Composition of 13 tested BGWs 
S3 USGS dataset: identifying suitable BGWs for MSED adoption

S4 Limiting current density and membrane resistance

S5 Ion transport number and membrane permselectivity: experiments and model

S6 Fertilizer costs

S7 Typical RO ion percent reductions

\section{References}

(1) United Nations, World Water Development Report 2020: Water and Climate Change. 2020; https://unesdoc.unesco.org/ark:/48223/pf0000372985.locale=en, Accessed June 10, 2020.

(2) Hunter, M. C.; Smith, R. G.; Schipanski, M. E.; Atwood, L. W.; Mortensen, D. A. Agriculture in 2050: Recalibrating Targets for Sustainable Intensification. BioScience 2017, 67, 386-391, DOI: $10.1093 / \mathrm{biosci/bix010.}$

(3) Foley, J. A five-step plan to feed the world. https://www.nationalgeographic.com/ foodfeatures/feeding-9-billion/, Accessed May 15, 2020.

(4) Stanton, J. S.; Anning, D. W.; Brown, C. J.; Moore, R. B.; McGuire, V. L.; Qi, S. L.; Harris, A. C.; Dennehy, K. F.; McMahon, P. B.; Degnan, J. R.; Böhlke, J. Brackish groundwater in the United States. U.S. Geological Survey Professional Paper 1833 2017, 185, DOI: https://doi.org/10.3133/pp1833.

(5) Cohen, B.; Lazarovitch, N.; Gilron, J. Upgrading groundwater for irrigation using monovalent selective electrodialysis. Desalination 2018, 431, 126 - 139, DOI: https://doi.org/10.1016/j.desal.2017.10.030.

(6) Song, L.; Schuetze, B.; Rainwater, K. Demonstration of a High Recovery and En- 
ergy Efficient RO System for Small-Scale Brackish Water Desalination. 2012; https://www.twdb.texas.gov/innovativewater/desal/projects/texastech/ doc/texas_tech_final_rpt.pdf, Accessed July 12, 2019.

(7) Strathmann, H. Electrodialysis, a mature technology with a multitude of new applications. Desalination 2010, 264, 268-288, DOI: https://doi.org/10.1016/j.desal.2010.04.069.

(8) Kawate, H.; Miyaso, K.; Takiguchi, M. Energy savings in salt manufacture by ion exchange membrane electrodialysis. Sixth International Symposium on Salt. Toronto, Canada, 24-28 May 1983, Vol. II, pp. 471-479.

(9) Saracco, G.; Zanetti, M. C. Ion transport through monovalent-anion-permselective membranes. Industrial \& Engineering Chemistry Research 1994, 33, 96-101, DOI: https://doi.org/10.1021/ie00025a013.

(10) Saracco, G. Transport properties of monovalent-ion-permselective membranes. $\quad$ Chemical Engineering Science 1997, 52, 3019-3031, DOI: https ://doi.org/10.1016/S0009-2509(97)00107-3.

(11) Luo, T.; Abdu, S.; Wessling, M. Selectivity of ion exchange membranes: A review. Journal of Membrane Science 2018, 555, 429-454, DOI: https://doi.org/10.1016/j.memsci.2018.03.051.

(12) Jiang, W.; Lin, L.; Xu, X.; Wang, H.; Xu, P. Physicochemical and electrochemical characterization of cation-exchange membranes modified with polyethyleneimine for elucidating enhanced monovalent permselectivity of electrodialysis. Journal of Membrane Science 2019, 572, 545-556, DOI: https ://doi .org/10.1016/j.memsci.2018.11.038.

(13) Ahdab, Y. D.; Rehman, D.; Lienhard, J. H. Brackish water desalination for greenhouses: improving groundwater quality for irrigation using monovalent 
selective electrodialysis reversal. Journal of Membrane Science 2020, DOI: https://doi.org/10.1016/j.memsci.2020.118072.

(14) Chen, G.; Wei, K.; Hassanvand, A.; Freeman, B.; Kentish, S. Single and binary ion sorption equilibria of monovalent and divalent ions in commercial ion exchange membranes. Water Research 2020, 175, 115681, DOI: https : //doi .org/10.1016/j . watres.2020.115681.

(15) Ahdab, Y. D.; Thiel, G. P.; Böhlke, J.; Stanton, J.; Lienhard, J. H. Minimum energy requirements for desalination of brackish groundwater in the United States with comparison to international datasets. Water Research 2018, 141, 387-404, DOI: https://doi.org/10.1016/j.watres.2018.04.015.

(16) Rehman, D.; Ahdab, Y.; Lienhard, J. H. Improving groundwater quality for irrigation using monovalent selective electrodialysis. IDA World Congress on Desalination and Water Use . Dubai, UAE, 20-24 Oct. 2019. No. IDAWC19-Rehman. https://dspace.mit.edu/handle/1721.1/124385.

(17) Qi, S.; Harris, A. Geochemical Database for the Brackish Groundwater Assessment of the United States: Data Release; U.S. Geological Survey, 2017; DOI: https://doi.org/10.5066/F72F7KK1.

(18) Ayers, R. S.; Westcot, D. W. Water quality for agriculture; Food and Agriculture Organization of the United Nations, 1985; Vol. 29.

(19) Cobban, B.; Faller, K. Electrodialysis and electrodialysis reversal: M38; American Water Works Association, 1995; Vol. 38.

(20) McGovern, R. K.; Weiner, A. M.; Sun, L.; Chambers, C. G.; Zubair, S. M.; Lienhard, J. H. On the cost of electrodialysis for the desalination of high salinity feeds. Applied Energy 2014, 136, 649-661, DOI: https ://doi .org/10.1016/j .apenergy .2014.09.050. 
(21) Firdaous, L.; Malériat, J.; Schlumpf, J.; Quéméneur, F. Transfer of Monovalent and Divalent Cations in Salt Solutions by Electrodialysis. Separation Science and Technology 2007, 42, 931-948, DOI: 10.1080/01496390701206413.

(22) Yermiyahu, U.; Tal, A.; Ben-Gal, A.; Bar-Tal, A.; Tarchitzky, J.; Lahav, O. Rethinking Desalinated Water Quality and Agriculture. Science 2007, 318, 920-921, DOI: 10.1126/science.1146339.

(23) Will, E.; Faust, J. PB1617-Irrigation Water Quality for Greenhouse Production. 1999; http: //trace.tennessee.edu/utk_agexcomhort/5, Accessed Aug 7, 2019.

(24) Nayar, K. G.; Lienhard, J. H. Brackish water desalination for greenhouse agriculture: Comparing the costs of RO, CCRO, EDR, and monovalent-selective EDR. Desalination 2020, 475, 114188, DOI: https ://doi.org/10.1016/j.desal.2019.114188.

(25) Alpha chemicals, Product: Calcium Sulfate Dihydrate - $\mathrm{CaSO}_{4} * 2 \mathrm{H}_{2} \mathrm{O}$. https:// alphachemicals.com/calcium_sulfate, Accessed July 17, 2019.

(26) PowerGrow Systems, Product: Epsom Salt (Magnesium Sulfate) Agricultural Grade. https://www.powergrowsystems.com/products/ epsom-salt-magnesium-sulfate-agricultural-grade?variant=40175466190, Accessed July 17, 2019.

(27) Tetreault, T. SBA Loan Rates 2019 - Current Interest Rates and How They Work. 2019; https://fitsmallbusiness.com/sba-loan-rates/, Accessed Jan 10, 2020.

(28) FUJIFILM Manufacturing Europe B.V., Jeroen van Nunen, Personal Communication to Yvana Ahdab. 2020; https: //www.fujifilmmembranes. com/, Accessed June 15, 2019.

(29) Ameridia Innovative Solutions, Inc., Daniel Bar, Personal Communication to Yvana Ahdab. 2019; http://www.eurodia.com/index.php/en/the-eurodia-group, Accessed June $15,2019$. 